
\title{
25 Research Square \\ Is bone health of young atopic dermatitis patients a significant healthcare problem?
}

\section{Sooyoung Kim}

Department of Dermatology, Soonchunhyang University Hospital

\section{Jimi Choi}

Division of Endocrinology and Metabolism, Department of Internal Medicine, Korea University College of Medicine

\section{Moon Kyun Cho}

Department of Dermatology, Soonchunhyang University Hospital

\section{Nam Hoon Kim}

Division of Endocrinology and Metabolism, Department of Internal Medicine, Korea University College of Medicine

\section{Sin Gon Kim}

Division of Endocrinology and Metabolism, Department of Internal Medicine, Korea University College of Medicine

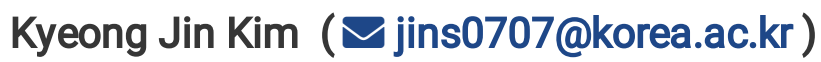

Division of Endocrinology and Metabolism, Department of Internal Medicine, Korea University College of Medicine

\section{Research Article}

Keywords: bone mineral density, osteoporosis, atopic dermatitis, young adults

Posted Date: July 12th, 2021

DOI: https://doi.org/10.21203/rs.3.rs-689559/v1

License: (c) (i) This work is licensed under a Creative Commons Attribution 4.0 International License. Read Full License 


\section{Abstract}

Background Atopic dermatitis (AD) incidence has increased over the past decades, especially among young adults. However, their bone health has not been clearly elucidated with discordant results.

Objective We aimed to investigate the bone mineral density (BMD) measured by double energy X-ray absorptiometry and Z-score at the lumbar spine, femur neck, and total femur to evaluate the risk of osteoporosis in men aged $<50$ years and premenopausal women with $A D$.

Methods The Korea National Health and Nutrition Examination Survey 2007-2009 data were used in this case-control cohort study. We included young AD patients (aged $19 \leq$ and $<50$ years) diagnosed by a doctor and compared these patients with 1:5 propensity score weighting controls by age, sex, body mass index (BMI), vitamin D level, and alcohol/smoking status.

Results We analyzed 311 (weighted $n=817,014$ ) AD patients and 1,555 (weighted $n=4,155,855$ ) controls. $B M D$ at the lumbar spine was significantly lower in the male AD group than in the male control group (mean $\pm \mathrm{SE}, 0.989 \pm 0.002$ vs. $0.954 \pm 0.016, \mathrm{P}=0.03$ ) while BMDs at the femur neck and total femur were comparable. For women, BMDs at the three sites were not significantly different between the AD and control groups. Low bone mass (defined by a Z-score of $\leq 2.0$ ) was not significantly different between the $A D$ and control groups in both sexes.

Conclusions Bone health, especially $\mathrm{BMD}$ and Z-score, in young $\mathrm{AD}$ patients were comparable with those without $A D$. AD was not a risk factor for low BMD.

\section{Introduction}

Atopic dermatitis (AD) is one of the most common inflammatory skin diseases affecting $15 \%-30 \%$ of children and $2 \%-10 \%$ of adults. ${ }^{1}$ The $A D$ prevalence has been increasing worldwide in recent decades. As $A D$ is a chronic inflammatory disease that usually begins in early childhood or adolescence, various comorbidities have been related to $A D$. Bone health problems in $A D$ patients have increasingly received attention because $A D$ is associated with risk factors for osteopenia and osteoporosis, including topical/systemic corticosteroid usage, less physical activity, malnutrition from food restriction, and AD with chronic inflammatory disease course. ${ }^{2}$ Haeck et al. reported that low bone mineral density (BMD), defined as a Z-score of $\leq-1$, was prevalent in adults with moderate-to-severe AD. ${ }^{5}$ Another study from the UK showed that patients with atopic eczema are associated with a $10 \%$ increased fracture risk compared with those without this condition. ${ }^{6}$ However, existing studies have several limitations. First, most results have included the elderly population, the major risk factor for osteoporosis and fracture, which cannot represent the bone health of the majority of young patients with AD. Second, multiple factors that affect bone health, such as sex, vitamin D level, alcohol consumption, smoking, and menopausal status, have not been fully applied in previous studies. ${ }^{1}$ 
Thus, we aimed to compare the BMD and Z-score between young AD patients and a general population with propensity score weighting for age, sex, body mass index (BMI), vitamin $\mathrm{D}$ level, alcohol/smoking status, and menopausal status using the data from the Korean National Health and Nutrition Examination Survey (KNHANES) 2007-2009.

\section{Materials And Methods}

\section{Study population and design}

The KNHANES is a cross-sectional nationwide survey conducted by the Korea Centers for Disease Control and Prevention (KCDC). ${ }^{7}$ It has been conducted periodically since 1998, and data were gathered through household interviews, standardized physical examinations, laboratory tests, and nutritional status assessments. The KNHANES IV, which only performed the BMD test, was conducted between 2007 and 2009 , including more than 260,000 primary sampling units each year. After applying the stratified, multistage clustered systemic sampling method, 19,841 of the 25,250 systemically selected individuals participated in this survey. We excluded (1) individuals aged $\geq 50$ and $<19$ years; (2) those with incomplete information on the atopic disease, $\mathrm{BMD}$ results, $\mathrm{BMI}$, and $25(\mathrm{OH}) \mathrm{D}$ level; or (3) postmenopausal women for any reason. We defined $A D$ based on the questionnaire about the previous history of $A D$ diagnosed by a doctor. All survey protocols were approved by the Institutional Review Board of the KCDC and we confirmed that all methods were performed in accordance with the relevant guidelines and regulation. All participants signed an informed consent form before the start of the survey.

\section{Bone densitometry and definition}

BMD at the lumbar spine, femoral neck, and total hip was measured using dual-energy X-ray absorptiometry (DXA, QDR4500A System; Hologic Inc., Waltham, MA, USA). BMD was expressed as the total bone mineral content $(\mathrm{g})$ divided by the area $\left(\mathrm{cm}^{2}\right)$. We calculated the Z-score of the lumbar spine, femoral neck, and total hip using the age- and sex-specific mean BMD $\left(\mathrm{g} / \mathrm{cm}^{2}\right)$ : (patient BMD-mean BMD of reference group)/(standard deviation [SD] of reference group). The SDs for the complex survey design were calculated using the Taylor series linearization method. ${ }^{11}$ The weighted mean and SD of the reference BMD for age and sex used to calculate the Z-score are described in Supplementary Table 1. According to the World Health Organization diagnostic classification, we defined low bone mass based on the expected range for their age group as a Z-score of $\leq-2.0$ and normal as a Z-score of $>-2.0{ }^{12}$

\section{Statistical analyses}

To obtain the appropriate nationally representative estimates, all analyses in this study were performed considering the complex survey design applied to the KNHANES. The propensity score weighting method was used to balance the variables between patients with and without AD. Individual propensity scores were calculated using multiple logistic regression models, including the presence of atopy as the dependent variable and age, sex, BMI, vitamin $\mathrm{D}$ level, alcohol consumption, smoking, and complex 
survey sampling weight as covariates. The final weight was obtained by multiplying the sampling weight by the propensity score weight. ${ }^{13}$ Continuous data were presented as the weighted mean and standard error of the mean for normally distributed variables and as medians and interquartile ranges (IQRs) for non-normally distributed variables. Categorical data were expressed as weighted frequencies and percentages. To compare the characteristics between patients with $A D$ and those without $A D$, we performed a weighted t-test for continuous variables and the Rao-Scott chi-square test for categorical variables. Finally, multiple logistic regression models considering the complex survey design were used to investigate the risk factors for low BMD group according to sex. In this model, the low BMD group was included as binary outcome variable and age, atopic dermatitis, body mass index, vitamin D deficiency, education, drinking and age at menarche (female only) were included as dependent variables. The results for logistic regression analysis were presented the odds ratios (ORs) and corresponding $95 \%$ confidence intervals (Cls). All reported P-values were two-sided, and statistical significance was set at $P<0.05$. All statistical analyses were performed using SAS software (version 9.4; SAS Institute Inc., Gary, NC, USA).

\section{Results}

\section{Participants' clinical characteristics}

This study included 311 (weighted $n=817,014$ ) patients with $A D$ and 8,972 (weighted $n=20,880,643$ ) without AD. The median ages at AD diagnosis were 18.7 years (IQR: 8.6-31.3 years) and 17.0 years (IQR 8.4-26.2 years) in male and female AD patients, with median durations of AD 9.8 years (IQR: 4.7-19.3 years) and 10.8 years (IQR: $5.5-19.1$ years), respectively. Meanwhile, $29.7 \%$ of male and $20.5 \%$ of female $A D$ patients received atopy treatment at the time of the survey. Among female patients, the median age of menarche was not significantly different between $A D$ patients and the control group. Higher family income was more frequently reported in the $A D$ group than in the control group among the female patients. Among female patients, no significant difference was observed in the history of oral contraceptive use between $A D$ patients and the control group. The experience of pregnancy and giving birth (55.4 vs. $65.0 \% ; P=0.040$ ) were significantly lower in the AD group than in the control group. Asthma was significantly higher in $A D$ patients in male ( 10.4 vs. $2.0 \% ; P=0.003)$ and female groups (5.5 vs. $2.0 \% ; P=0.022$ ). Depression mood was not significantly different in $A D$ patients compared with the control group in both sexes. Sickness at 1 month was significantly higher in AD patients than in the control group ( 16.6 vs. $8.6 \% ; \mathrm{P}=0.003)$; absence at 1 month was not significantly different among the female group (Table 1).

\section{Bone mineral density and Z-score between the $A D$ and control groups}

$B M D$ at the lumbar spine was lower in male AD patients than in the control group (mean $\pm S E, 0.954 \pm$ 0.016 vs. $0.989 \pm 0.002 ; P=0.03)$. BMD at the total femur was lower in $A D$ patients than in the control group $(0.977 \pm 0.012$ vs. $0.999 \pm 0.002 ; P=0.08)$, with no significant difference. For female $A D$ patients, BMDs at the lumbar, femur neck, and total femur were not significantly different between the AD and control groups (Table 2). The rates of low bone mass, defined by the lowest Z-score $\leq-2.0$ in the three 
measured sites (lumbar spine, total femur, and femoral neck), were not significantly different in the AD group compared with the control group in both male (3.8\% vs. $2.7 \% ; P=0.56)$ and female patients $(6.4 \%$ vs. $3.3 \% ; P=0.40$ ) (Table 3 ).

\section{Risk factors for low BMD in all participants stratified by sex}

We further calculated the crude- and adjusted odds ratios (aORs) to determine the risk factors for low BMD among all participants stratified by sex. Older age was associated with increased odds of low BMD with a greater effect of aging on bone loss in women than in men. A higher BMI was associated with decreased odds of lower BMI in both sexes. In female, having vitamin D deficiency was associated with increased odds of low while in male, vitamin D deficiency was not associated with low BMD. Atopic dermatitis itself was not associated with low BMD in both male and female (Table 4).

\section{Relationship between clinical characteristics and low BMD among AD patients}

We compared the clinical characteristics of the normal and low BMD group among AD patients stratified by sex. Among male AD patients, the low BMD group was diagnosed with $A D$ at younger age, lower $B M I$, and frequently resided in the rural areas compared with the normal BMD group (Suppl. Table 2).

In female $A D$ patients, the low BMD group were diagnosed with $A D$ at earlier age and longer $A D$ duration. The low BMD group had lower BMI, less educated, lower vitamin D level, later age at menarche, and higher number of pregnancies compared with the normal BMD group (Suppl. Table 3).

\section{Discussion}

This retrospective weighted case-control study demonstrated that BMDs and Z-scores were comparable between the $A D$ and control groups, except that $B M D$ at the lumbar spine was slightly lower in the $A D$ male patients than in the control group. The actual prevalence of low bone mass (Z-score $\leq-2.0$ ) in the $A D$ group and that in the non- $A D$ group were not significant in either sex (male: $3.8 \%$ vs. $2.7 \%, P=0.56$; female: $6.4 \%$ vs. $3.3 \%, P=0.40$ ). $A D$ was not a risk factor for low $B M D$, while older age and lower $B M I$ were significantly associated with low BMD in both male and female among all participants. Vitamin $D$ deficiency (defined as 25-hydroxy vitamin $D<20 \mathrm{ng} / \mathrm{dL}$ ), a well-known risk factor for osteoporosis, ${ }^{14}$ was significantly associated with low BMD only in female. A few studies have evaluated the prevalence of low $B M D$ and osteoporosis in young patients with $A D$, particularly for the accurate measurement of $B M D$ using DXA. Our study, using a large sample, provides evidence that BMD and Z-score may not be a significant health burden in young AD patients.

In baseline characteristics after propensity score weighting, a lower number of pregnancies and births were reported among women with $A D$, although oral contraceptive use was comparable. Higher frequency of single or never-married status of $A D$ patients, ${ }^{16}$ psychological distress, including depression, anxiety, and lower self-esteem of $A D$ people, ${ }^{17,18}$ may affect their partner relationships ${ }^{19}$, which explains the low pregnancy and birth rates among AD patients. AD patients had a higher incidence of asthma consistent 
with the reports of previous studies, ${ }^{16,20}$ while no difference was found in the incidence of depression between the $A D$ and non-AD groups, which was frequently reported previously. ${ }^{17}$ Considering that we matched vitamin $D$ levels, which have been significantly low in $A D$ patients ${ }^{21}$ and negatively correlated with the severity of $A D,{ }^{22}$ vitamin $D$ could primarily be attributed to comorbid depression in $A D$ patients. There is adequate evidence showing a positive relationship between vitamin $D$ deficiency and depression, ${ }^{23}$ suggesting its role in the synthesis of dopamine, noradrenaline, and adrenaline that are implicated in mood disorders. ${ }^{24}$ Women with $A D$ were more likely to fall ill within 1 month than non-AD women, but no significant difference was found within 1 month of absence. According to a meta-analysis on the influence of $A D$ on work-life, $A D$ affects sick leave, possibly affecting job choice, and leading to change or loss of job. ${ }^{25}$

We found a significant decrease in BMD in the lumbar spine of male AD patients. It could be considered as an early phenomenon of $B M D$ reduction in $A D$ patients because the trabecular bone of the lumbar spine is more responsive to metabolic changes than the cortical bone of the femoral neck and distal radius. ${ }^{26,27}$ However, BMD change could be interpreted as reflecting a "real" change only if the random error of the DXA system is exceeded. The random error or least significant change has been described to be between $3.3 \%$ and $4.7 \%$ for the total hip. ${ }^{28,29}$ The decrease in BMD in AD patients was $3.5 \%$ in our study compared with that in non-AD controls, which is marginal; it appears to be not a relevant decrease clinically.

Previous studies on bone health, including low bone mass, osteopenia, osteoporosis, and fracture or injury risk, have shown conflicting results. A study from Finland including 28 adult AD patients suggested that the BMDs of patients with AD did not differ from those of healthy controls ${ }^{2}$. Also, in children with moderate to severe AD, low BMD (defined as a Z score <-2) did not occur more frequently. ${ }^{30}$ According to the previous study, low BMD was not associated with either the use of topical corticosteroids or systemic treatments (oral corticosteroids and/or cyclosporine) in children with moderate-to-severe AD. ${ }^{30}$ By contrast, Haeck et al. reported that low BMD, defined as a Z-score of $\leq-1$, was found in one-third of adults with moderate-to-severe $A D$, predominantly male and relatively young individuals, independent of the cumulative dose of topical corticosteroids. ${ }^{5}$ In another study of children affected by severe AD, using topical corticosteroids plus oral cyclosporine group had a lower lumbar spine BMD compared with those who only used topical corticosteroids, indicating that low bone mass was primarily mediated by cyclosporine rather than by topical corticosteroids. ${ }^{27}$ In addition, previous population-based studies from Taiwan and the United States have shown a significant association between adult AD and osteoporosis ${ }^{4,31}$ and epidemiologic studies from the British and United States demonstrated increased fracture risk in adult AD patients. ${ }^{32,33}$ These inconsistent conclusions are due to the differences in population, sample size, a cut-off value of Z-score, the definition of osteoporosis, history of AD treatments, and follow-up duration requiring more large-scale and long-term longitudinal studies.

Of note, we revealed that $A D$ itself was not an independent risk factor for low bone mass. Instead, it seemed $A D$ patients have risk factors for osteoporosis and fracture, such as low vitamin D level, lower 
activity, and systemic corticosteroid or immunosuppressant use, which may have a greater effect on bone health. Vitamin D plays a central role in calcium metabolism and skeletal structure. At the same time, vitamin $D$ has been implicated in the pathogenesis of $A D$ by regulating the synthesis of structural proteins of the epidermal barrier and regulating immune response. ${ }^{34}$ Choi et al. demonstrated that the prevalence rates of vitamin D insufficiency was $47.3 \%$ in men and $64.5 \%$ in women in South Korea using the KNHANES IV. More strikingly, vitamin D insufficiency was a great threat to the younger generation, and those in their twenties had the highest prevalence of vitamin $D$ insufficiency in both men and women. Therefore, we performed propensity score weighting not only for age and sex, but also for vitamin D level, alcohol consumption, and smoking habit, which affect osteoporosis. Our study design had a significant strength as it evaluates the impact of $A D$ on $B M D$ and osteoporosis.

There are several potential reasons for the lack of significant association between $A D$ and low $B M D$, and $A D$ itself was not an independent risk factor in our study. Type 2 inflammation associated with AD might actually protect against osteoporosis because Th2 cytokines are recognized to have an osteoprotective effect, enhancing the anabolic effects of parathyroid hormone, and decreasing the receptor activator of nuclear factor-kB ligand/osteoprotegerin ratio, leading to inhibition of bone resorption. ${ }^{35}$ Oral corticosteroids are a well-recognized risk factor for osteoporosis; however, in a population study by Lowe et al $^{6}$., no significant association was found between oral steroid use and fracture risk, possibly because of the small number of participants who had been receiving long-term steroids as treatment for AD. There is little or no evidence to suggest that topical steroids, even potent topical steroids, are associated with osteoporosis. ${ }^{5,27,28,30}$

In the further analyses comparing the low BMD and normal BMD groups among AD patients stratified by sex, those who live in rural areas (for male $A D$ ) and less educated (for female $A D$ ) were prone to have low bone mass. In addition, low vitamin $D$ level and higher vitamin $D$ deficiency frequency was presented in female $A D$ patients while inverse association was found in male $A D$ patients, suggesting that the vitamin $D$ deficiency had greater effects especially in women AD patients. The late age of menarche and a higher number of pregnancies/giving births were associated with low bone mass among women with AD. Some studies have suggested that possibly due to the shorter exposure to circulating estrogen, a vital hormonal factor for bone formation, late age at menarche is associated with an increased risk of osteoporosis and osteoporotic fractures. ${ }^{33,37-39}$ It also has been shown that during pregnancy, bone absorption is increased. ${ }^{40}$ Importantly, we found that early onset and longer duration of AD were associated with low bone mass. Taken together, physicians would be able to identify those who are at risk of low bone mass among $A D$ patients and can offer tailored counseling according to demographics, age of onset and duration of $A D$, and obstetric history in women with $A D$.

Nevertheless, several limitations of this study need to be mentioned. First, the KNHANES is a retrospective cross-sectional study, limiting the interpretation of causality between $A D$ and osteoporosis. In addition, there was no long-term follow-up data on future osteoporosis and fracture risk in this young AD patient. Therefore, a more careful interpretation is required to obtain a definite conclusion. Another major 
limitation of this study was the lack of information on the AD treatment that may affect BMD in $A D$ patients. Lastly, we did not include biochemical information, such as calcium, phosphorus, parathyroid hormone, and thyroid function tests. This limitation may lead to the potential pitfall of passing over other secondary causes of osteoporosis in the young population.

In conclusion, this study assessed the bone health status of young adult patients with $A D$ and investigated the associated risk factors, compared with a general population with propensity score weighting for age, sex, BMI, vitamin D level, and alcohol/smoking status. The BMDs at all sites were comparable between the $A D$ and control groups. Z-scores below the expected range were not significantly different between the two groups. Although the increased risk of osteoporosis and fracture in AD patients is still debatable, our study using a large and meticulous case-control propensity score weighting design provides evidence that supports further long-term and large-scale investigation in AD patients.

\section{Declarations}

Funding source: None.

Conflict of interest: The authors declare they have no conflicts of interest.

Availability of data and material (data transparency): The dataset generated during the current study is available upon reasonable request from the corresponding author, Kyeong Jin Kim, (jins0707@korea.ac.kr).

Code availability (software application or custom code): The code generated during the current study is available upon reasonable request from the corresponding author, Kyeong Jin Kim, (jins0707@korea.ac.kr).

\section{References}

1. Bawany F, Beck LA, Järvinen KM. Halting the March: Primary prevention of atopic dermatitis and food allergies. J Allergy Clin Immunol Pract. In Practice. 2020;8:860-875. doi:10.1016/j.jaip.2019.12.005

2. Aalto-Korte K, Turpeinen M. Bone mineral density in patients with atopic dermatitis. Br J Dermatol 1997;136:172-175.

3. Sirufo MM, De Pietro F, Bassino EM, et al. Osteoporosis in skin diseases. Int J Mol Sci 2020;21:1-17.

4. Wu C-Y, Lu Y-Y, Lu C-C, et al. Osteoporosis in adult patients with atopic dermatitis: A nationwide population-based study. PLoS One 2017; 12:e0171667.

5. Haeck IM, Hamdy NAT, Timmer-de Mik L, et al. Low bone mineral density in adult patients with moderate to severe atopic dermatitis. Br J Dermato/ 2009;161:1248-1254.

6. Lowe KE, Mansfield KE, Delmestri A, et al. Atopic eczema and fracture risk in adults: a populationbased cohort study. J Allergy Clin Immunol 2020;145:563-571.e8. 
7. Kweon S, Kim Y, Jang M, et al. Data resource profile: the Korea national health and nutrition examination survey (KNHANES). Int J Epidemio/ 2014;43:69-77.

8. Park EJ, Joo IW, Jang M-J, et al. Prevalence of osteoporosis in the Korean population based on Korea National Health and Nutrition Examination Survey (KNHANES), 2008-2011. Yonsei Med J 2014;55:1049-1057.

9. Park S, Lee S, Hwang J, Kwon J-W. The impact of weight misperception on health-related quality of life in Korean adults (KNHANES 2007-2014): a community-based cross-sectional study. BMJ Open 2017;7:e016098.

10. Park KH, Lim JS, Kim KM, et al. Z-score discordance and contributing factors in healthy premenopausal women with low bone mineral density: the Korean National Health and Nutrition Examination Survey 2008-9. J Bone Miner Metab 2016;34:668-677.

11. Model Assisted Survey Sampling | Carl-Erik Särndal | Springer. Available at: https://www.springer.com/gp/book/9780387406206 (last accessed 29 March 2021).

12. Assessment of fracture risk and its application to screening for postmenopausal osteoporosis: report of a WHO Study Group. World Health Organization 1994;843:1-129

13. Karabon P. Applying propensity score methods to complex survey data using PROC PSMATCH.

14. Holick MF. Vitamin D deficiency. N Engl J Med 2007;357:266-281.

15. Okada H, Kuhn C, Feillet H, Bach JF. The "hygiene hypothesis" for autoimmune and allergic diseases: an update. Clin Exp Immunol 2010;160:1-9.

16. Lee JS, Kim JM, Seok J, Kim BJ. Correlation between socio-economic status and atopic dermatitis in Korean adults: the Korea national health and nutrition examination survey (2007-2014). J Eur Acad Dermatol Venereol 2017;31:1509-1515.

17. Lee SH, Lee SH, Lee SY, et al. Psychological health status and health-related quality of life in adults with atopic dermatitis: a nationwide cross-sectional study in South Korea. Acta Derm Venereol 2018;98:89-97.

18. Wittkowski A, Richards HL, Griffiths CEM, Main CJ. The impact of psychological and clinical factors on quality of life in individuals with atopic dermatitis. J Psychosom Res 2004;57:195-200.

19. Misery L, Seneschal J, Reguiai Z, et al. The impact of atopic dermatitis on sexual health. $J$ Eur Acad Dermatol Venereo/ 2019;33:428-432.

20. Silverberg JI, Hanifin JM. Adult eczema prevalence and associations with asthma and other health and demographic factors: a US population-based study. J Allergy Clin Immunol 2013;132:11321138.

21. Cheng HM, Kim S, Park GH, et al. Low vitamin D levels are associated with atopic dermatitis, but not allergic rhinitis, asthma, or IgE sensitization, in the adult Korean population. J Allergy Clin Immunol 2014;133:1048-1055.

22. Peroni DG, Piacentini GL, Cametti E, et al. Correlation between serum 25-hydroxyvitamin D levels and severity of atopic dermatitis in children. Br J Dermatol 2011;164:1078-1082. 
23. Parker GB, Brotchie H, Graham RK. Vitamin D and depression. J Affect Disord 2017;208:56-61.

24. Eyles DW, Burne THJ, McGrath JJ. Vitamin D, effects on brain development, adult brain function and the links between low levels of vitamin D and neuropsychiatric disease. Front Neuroendocrinol 2013;34:47-64.

25. Nørreslet LB, Ebbehøj NE, Ellekilde Bonde JP, et al. The impact of atopic dermatitis on work life - a systematic review. J Eur Acad Dermatol Venereol 2018;32:23-38.

26. Tsurusaki K, Ito M, Hayashi K. Differential effects of menopause and metabolic disease on trabecular and cortical bone assessed by peripheral quantitative computed tomography (pQCT). Br J Radiol 2000;73:14-22.

27. Pedreira CC, King E, Jones G, et al. Oral cyclosporin plus topical corticosteroid therapy diminishes bone mass in children with eczema. Pediatr Dermato/ 2007;24:613-620.

28. Van Velsen SGA, Haeck IM, Knol MJ, et al. Two-year assessment of effect of topical corticosteroids on bone mineral density in adults with moderate to severe atopic dermatitis. J Am Acad Dermatol 2012;66:691-693.

29. Baim S, Wilson CR, Lewiecki EM, et al. Precision assessment and radiation safety for dual-energy Xray absorptiometry: position paper of the International Society for Clinical Densitometry. J Clin Densitom 2005;8:371-378.

30. Van Velsen SGA, Knol MJ, Van Eijk RLA, et al. Bone mineral density in children with moderate to severe atopic dermatitis. J Am Acad Dermatol 2010;63:824-831.

31. Shaheen MS, Silverberg JI. Atopic dermatitis is associated with osteoporosis and osteopenia in older adults. J Am Acad Dermatol 2019;80:550-551.

32. Lowe KE, Mansfield KE, Delmestri A, et al. Atopic eczema and fracture risk in adults: a populationbased cohort study. J Allergy Clin Immunol 2020;145:563-571.e8.

33. Garg N, Silverberg Jl. Association between eczema and increased fracture and bone or joint injury in adults: a US population-based study. JAMA Dermatol 2015;151:33-41.

34. Umar M, Sastry KS, Al Ali F, et al. Vitamin D and the pathophysiology of inflammatory skin diseases. Skin Pharmacol Physiol 2018;31:74-86.

35. Arkwright PD, Mughal MZ. Vertebral, pelvic, and hip fracture risk in adults with severe atopic dermatitis. J Allergy Clin Immunol 2020;145:487-488.

36. Van Velsen SGA, Knol MJ, Van Eijk RLA, et al. Bone mineral density in children with moderate to severe atopic dermatitis. J Am Acad Dermatol 2010;63:824-831.

37. Gerdhem P, Obrant KJ. Bone mineral density in old age: The influence of age at menarche and menopause. J Bone Miner Metab 2004;22:372-375.

38. Silman AJ. Risk factors for Colles' fracture in men and women: results from the European Prospective Osteoporosis Study. Osteoporos Int 2003;14:213-218.

39. Eastell R. Role of oestrogen in the regulation of bone turnover at the menarche. J Endocrinol 2005;185:223-234. 
40. Salari P, Abdollahi M. The influence of pregnancy and lactation on maternal bone health: a systematic review. J Family Reprod Health 2014;8:135-148.

\section{Tables}

Table 1. Baseline characteristics after propensity score weighting 


\begin{tabular}{|c|c|c|c|c|c|c|}
\hline & \multicolumn{2}{|c|}{ Male $(n=11,585,713)$} & \multirow[t]{2}{*}{$P$} & \multicolumn{2}{|c|}{ Female $(n=10,111,944)$} & \multirow[t]{2}{*}{$P$} \\
\hline & $\begin{array}{l}\text { Non- } \\
\text { atopic }\end{array}$ & Atopic & & $\begin{array}{l}\text { Non- } \\
\text { atopic }\end{array}$ & Atopic & \\
\hline & $\begin{array}{l}11,170,803 \\
(96.4)\end{array}$ & $\begin{array}{l}414,910 \\
(3.6)\end{array}$ & & $\begin{array}{l}9,709,840 \\
(96.0)\end{array}$ & $402,104(4.0)$ & \\
\hline Age, years (median, IQR) & $\begin{array}{l}34.6 \\
(26.9- \\
41.5)\end{array}$ & $\begin{array}{l}35.3 \\
(28.1- \\
43.1)\end{array}$ & 0.388 & $\begin{array}{l}34.5 \\
(26.8- \\
40.9)\end{array}$ & $\begin{array}{l}34.2(26.2- \\
41.0)\end{array}$ & 0.833 \\
\hline $\mathrm{BMI}($ mean $\pm \mathrm{SE}), \mathrm{kg} / \mathrm{m}^{2}$ & $24.1(0.07)$ & $\begin{array}{l}24.0 \\
(0.32)\end{array}$ & 0.565 & $\begin{array}{l}22.5 \\
(0.07)\end{array}$ & $22.4(0.31)$ & 0.749 \\
\hline $\begin{array}{l}\text { Age at diagnosis of } \\
\text { atopic dermatitis, years } \\
\text { (median, IQR) }\end{array}$ & & $\begin{array}{l}18.7 \\
(8.6- \\
31.3)\end{array}$ & & & $\begin{array}{l}17.0(8.4- \\
26.2)\end{array}$ & \\
\hline $\begin{array}{l}\text { Duration of atopic } \\
\text { dermatitis, years (median, } \\
\text { IQR) }\end{array}$ & & $\begin{array}{l}9.8(4.7- \\
19.3)\end{array}$ & & & $\begin{array}{l}10.8(5.5- \\
19.1)\end{array}$ & \\
\hline Atopy treatment, n (\%) & & $\begin{array}{l}112587 \\
(29.7)\end{array}$ & & & $82610(20.5)$ & \\
\hline Education & & & 0.728 & & & 0.140 \\
\hline$<$ High school & $\begin{array}{l}760,972 \\
(6.8)\end{array}$ & $\begin{array}{l}35,450 \\
(8.5)\end{array}$ & & $\begin{array}{l}875369 \\
(9.0)\end{array}$ & $33,600(8.4)$ & \\
\hline High school & $\begin{array}{l}5,429,479 \\
(48.6)\end{array}$ & $\begin{array}{l}179,275 \\
(43.2)\end{array}$ & & $\begin{array}{l}4,851,447 \\
(50.0)\end{array}$ & $\begin{array}{l}162,134 \\
(40.3)\end{array}$ & \\
\hline College or more & $\begin{array}{l}4,975,112 \\
(44.6)\end{array}$ & $\begin{array}{l}200,185 \\
(48.2)\end{array}$ & & $\begin{array}{l}3,983,024 \\
(41.0)\end{array}$ & $\begin{array}{l}206,369 \\
(51.3)\end{array}$ & \\
\hline $\begin{array}{l}\text { Monthly family income } \\
\text { (quartile), n (\%) }\end{array}$ & & & 0.969 & & & 0.019 \\
\hline Lowest & $\begin{array}{l}2,887,602 \\
(26.1)\end{array}$ & $\begin{array}{l}106,009 \\
(25.7)\end{array}$ & & $\begin{array}{l}2,565,049 \\
(26.7)\end{array}$ & $\begin{array}{l}114,897 \\
(28.6)\end{array}$ & \\
\hline Lower middle & $\begin{array}{l}2,805,126 \\
(25.4)\end{array}$ & $\begin{array}{l}104,717 \\
(25.3)\end{array}$ & & $\begin{array}{l}2,499,467 \\
(26.0)\end{array}$ & $62,343(15.5)$ & \\
\hline Higher middle & $\begin{array}{l}2,737,561 \\
(24.8)\end{array}$ & $\begin{array}{l}112,551 \\
(27.2)\end{array}$ & & $\begin{array}{l}2,400,287 \\
(25.0)\end{array}$ & $91,443(22.7)$ & \\
\hline Highest & $\begin{array}{l}2,612,419 \\
(23.7)\end{array}$ & $\begin{array}{l}89,963 \\
(21.8)\end{array}$ & & $\begin{array}{l}2,135,211 \\
(22.2)\end{array}$ & $\begin{array}{l}133,421 \\
(33.2)\end{array}$ & \\
\hline Residence area, n (\%) & & & 0.087 & & & 0.993 \\
\hline Urban & $\begin{array}{l}9,451,039 \\
(84.6)\end{array}$ & $\begin{array}{l}377,968 \\
(91.1)\end{array}$ & & $\begin{array}{l}8,361,707 \\
(86.1)\end{array}$ & $\begin{array}{l}346,158 \\
(86.1)\end{array}$ & \\
\hline Rural & $1,719,764$ & 36,942 & & $1,348,133$ & 55,946 (13.9) & \\
\hline
\end{tabular}


Alcohol, n (\%)

Never drinker

Ex-/current drinker

0.391

345,094 (3.1)

$10,825,708$

(96.9)
22,013

(5.3)

392,897

(94.7)
712,623

(7.3)

$8,997,217 \quad 366,308$

(92.7)

(91.1)

$35,796(8.9)$

Smoking, n (\%)

0.773

0.752

Never smoker

$2,387,107$

(21.4)

93,719

(22.6)

$8,134,305$

(83.8)

332,559

$8,783,696 \quad 321,191$

(78.6)

(77.4)

$1,575,535 \quad 69,545(17.3)$

(16.2)

Moderate exercise, $\mathrm{n}(\%)$

0.239

0.247

Yes

$1,451,455$

(13.0)

38,957

(9.4)

$1,057,025$

(10.9)

No

$9,717,518$

(87.0)

375,953

(90.6)

$8642,770 \quad 344,617$

(89.1)

(85.7)

Vitamin D level, $\mathrm{ng} / \mathrm{dL}$

(median, IQR)
17.2

(13.5-

22.1)
17.0

(13.8-

22.1)
0.716

14.8

(11.7-

18.7)

Age at menarche
(median, IQR)

OCP use, $n(\%)$

Pregnancy experience, $\mathrm{n}$

(\%)

Number of pregnancies,

median (IQR)

Birth experience, $\mathrm{n}(\%)$

Previous asthma

diagnosis, $\mathrm{n}(\%)$

Depression mood, $\mathrm{n}(\%)$

Absence in 1 month, $\mathrm{n}$

(\%)

Sickness in 1 month, $\mathrm{n}$ (\%)
13.1

(12.1-

14.1)

$-$

$1,106,502 \quad 38,651(10.0) \quad 0.434$ (12.1)

$6,488,925 \quad 229,307(59.5) \quad 0.012$ (70.9)

$1.5(0-$

$1.1(0-2.5)$

0.129

2.8)

$6,312,481 \quad 222,571$

(65.0)

(55.4)

0.040

$196,188 \quad 22,043(5.5) \quad 0.022$

(2.0)

43,281

(10.4)

0.003

(2.0)

0.558

349,371

$16,025(4.0)$

0.838

(1.1)

(0.6)

(3.6)

362,195

(3.4)

23,418

(6.1)

0.404

393,547

(4.9)

$29,706(8.0)$

0.106

538,454

(4.8)

37,095

(8.9)
0.373

836,511 (8.6)
$66,796(16.6) \quad 0.003$ 
Abbreviations: $\mathrm{BMI}$, body mass index; IQR, interquartile range; OCP, oral contraceptive pill; $\mathrm{SE}$, standard error

Table 2. Comparisons of BMD at the lumbar spine, femur neck, and total hip between atopic and nonatopic patients

\begin{tabular}{|lllllll|}
\hline & $\begin{array}{l}\text { Lumbar spine BMD } \\
\left(\mathrm{g} / \mathrm{cm}^{2}\right)\end{array}$ & $P$ & $\begin{array}{l}\text { Femur neck BMD } \\
\left(\mathrm{g} / \mathrm{cm}^{2}\right)\end{array}$ & $P$ & $\begin{array}{l}\text { Total hip } \\
\text { BMD }\left(\mathrm{g} / \mathrm{cm}^{2}\right)\end{array}$ & \\
\hline Men & & $\mathbf{0 . 0 3 0}$ & & 0.102 & & 0.080 \\
\hline Non-atopic & $0.989 \pm 0.002$ & & $0.863 \pm 0.002$ & & $0.999 \pm 0.002$ & \\
\hline Atopic & $0.954 \pm 0.016$ & & $0.843 \pm 0.011$ & & $0.977 \pm 0.012$ & \\
\hline Women & & 0.744 & & 0.936 & & 0.411 \\
\hline Non-atopic & $0.985 \pm 0.002$ & & $0.765 \pm 0.002$ & & $0.898 \pm 0.002$ & \\
\hline Atopic & $0.979 \pm 0.016$ & & $0.766 \pm 0.010$ & & $0.890 \pm 0.010$ & \\
\hline $\begin{array}{l}\text { P for } \\
\text { interaction* }\end{array}$ & & 0.213 & & 0.215 & & 0.439 \\
\hline
\end{tabular}

Abbreviations: BMD, bone mineral density

Data are expressed as mean \pm standard error.

*P for interaction between sex and atopy

Table 3. Comparisons of Z-score at the lumbar spine, femur neck, and total hip between atopic and nonatopic patients 


\begin{tabular}{|c|c|c|c|c|c|c|c|}
\hline & \multicolumn{2}{|l|}{ Male } & \multicolumn{2}{|l|}{ Non-atopy } & \multicolumn{2}{|l|}{ Atopy } & $P$ \\
\hline & \multicolumn{2}{|c|}{$N=1,1585,713$} & \multicolumn{2}{|c|}{$N=1,1170,803$} & \multicolumn{2}{|c|}{$N=414,910$} & \\
\hline Lumbar spine & & & & & & & 0.139 \\
\hline Z-score >-2.0 & $11,176,052$ & $(98.6)$ & $10,777,887$ & $(98.6)$ & 398,165 & $(96.7)$ & \\
\hline Z-score $\leq-2.0$ & 161,679 & (1.4) & 148,098 & (1.4) & 13,580 & (3.3) & \\
\hline Femoral neck & & & & & & & 0.830 \\
\hline Z-score >-2.0 & $11,430,483$ & $(99.2)$ & $11,026,396$ & $(99.2)$ & 404,088 & (99.3) & \\
\hline Z-score $\leq-2.0$ & 91,644 & $(0.8)$ & 88,805 & $(0.8)$ & 2,839 & $(0.7)$ & \\
\hline Total hip & & & & & & & 0.834 \\
\hline Z-score >-2.0 & 193,267 & (98.3) & $10,927,793$ & $(98.3)$ & 401,067 & $(98.6)$ & \\
\hline Z-score $\leq-2.0$ & $11,328,860$ & (1.7) & 187,408 & $(1.7)$ & 5,860 & (1.4) & \\
\hline Normal/Low & & & & & & & 0.555 \\
\hline Normal group & $11,263,628$ & (97.2) & $10,864,302$ & (97.3) & 399,326 & $(96.2)$ & \\
\hline \multirow[t]{3}{*}{ Low Z-score group* } & 322,085 & (2.8) & 306,501 & $(2.7)$ & 15,584 & (3.8) & \\
\hline & Female & & Non-atopy & & Atopy & & $P$ \\
\hline & $N=10,111,94$ & & $N=9,709,840$ & & $N=402,10$ & & \\
\hline Lumbar spine & & & & & & & 0.213 \\
\hline Z-score >-2.0 & $9,690,159$ & $(98.1)$ & $9,312,514$ & (98.3) & 377,645 & (94.6) & \\
\hline Z-score $\leq-2.0$ & 183,188 & $(1.9)$ & 161,638 & $(1.7)$ & 21,550 & (5.4) & \\
\hline Femoral neck & & & & & & & 0.406 \\
\hline Z-score >-2.0 & $9,821,940$ & $(98.7)$ & $9,429,111$ & $(98.7)$ & 392,829 & $(99.4)$ & \\
\hline Z-score $\leq-2.0$ & 128,695 & (1.3) & 126,379 & (1.3) & 2,316 & $(0.6)$ & \\
\hline Total hip & & & & & & & 0.214 \\
\hline Z-score >-2.0 & $9,787,971$ & $(98.4)$ & $9,394,880$ & (98.3) & 393,091 & (99.5) & \\
\hline Z-score $\leq-2.0$ & 162,664 & (1.6) & 160,610 & $(1.7)$ & 2,053 & $(0.5)$ & \\
\hline Normal/low & & & & & & & 0.395 \\
\hline Normal-BMD group & $9,768,365$ & (96.6) & $9,392,180$ & $(96.7)$ & 376,185 & (93.6) & \\
\hline Low Z-score group* & 343,579 & (3.4) & 317,660 & (3.3) & 25,919 & (6.4) & \\
\hline
\end{tabular}

*Z-score $\leq-2.0$ in at least one of three sites 
Table 4. Crude and adjusted odds ratios (ORs) for low BMD (defined as Z-score $\leq-2.0$ ) among all participants according to sex.

\begin{tabular}{|c|c|c|c|}
\hline & Crude OR (95\% Cl) & Adjusted OR* (95\% Cl) & $P$ \\
\hline \multicolumn{4}{|l|}{ Male } \\
\hline Age (per 1year) & $1.01(0.98-1.03)$ & $1.03(1.01-1.06)$ & 0.013 \\
\hline Atopic dermatitis & $1.38(0.47-4.09)$ & $1.62(0.52-5.07)$ & 0.406 \\
\hline BMI (per $\left.1 \mathrm{~kg} / \mathrm{m}^{2}\right)$ & $0.67(0.61-0.73)$ & $0.66(0.60-0.71)$ & $<0.001$ \\
\hline Vitamin D deficiency & $1.23(0.78-1.95)$ & $1.23(0.76-1.98)$ & 0.404 \\
\hline Education $\leq$ High school & $1.48(1.01-2.18)$ & $1.33(0.89-1.99)$ & 0.170 \\
\hline Ex-/current drinker & $2.90(0.90-9.42)$ & $2.94(0.84-10.32)$ & 0.093 \\
\hline \multicolumn{4}{|l|}{ Female } \\
\hline Age (per 1year) & $1.02(0.99-1.05)$ & $1.05(1.03-1.08)$ & $<0.001$ \\
\hline Atopic dermatitis & $2.04(0.38-10.94)$ & $2.02(0.39-10.35)$ & 0.399 \\
\hline BMI (per $\left.1 \mathrm{~kg} / \mathrm{m}^{2}\right)$ & $0.74(0.68-0.80)$ & $0.68(0.63-0.74)$ & $<0.001$ \\
\hline Vitamin D deficiency & $1.75(1.04-2.94)$ & $1.99(1.15-3.44)$ & 0.014 \\
\hline Education $\leq$ High school & $1.21(0.82-1.78)$ & $1.47(1.02-2.11)$ & 0.039 \\
\hline Ex-/current drinker & $0.88(0.46-1.67)$ & $0.88(0.45-1.71)$ & 0.697 \\
\hline Age at menarche (per 1 1year) & $1.21(1.01-1.44)$ & $1.10(0.94-1.29)$ & 0.229 \\
\hline
\end{tabular}

Abbreviations: OR, odds ratio; $\mathrm{Cl}$, confidence interval; $\mathrm{BMI}$, body mass index;

Vitamin $D$ deficiency defined by 25 -hydroxy vitamin $D<20 \mathrm{ng} / \mathrm{dL}$.

*Propensity scores were calculated by two separated multiple logistic regression models according to sex. The models included the presence of atopy as dependent variable and age, body mass index, vitamin D deficiency, smoking, drinking, and sampling weight as independent variables.

\section{Supplementary Files}

This is a list of supplementary files associated with this preprint. Click to download.

- BMDinAtopySupplementalTableSciRep.docx 